\title{
Actual analysis of modern therapeutical aspects in HTA treatment and associated comorbidities
}

\author{
Analiza actuală a aspectelor terapeutice moderne în tratamentul HTA şi al \\ comorbidităţilor asociate
}

\author{
Gabriel Cristian Bejan, Ana Maria Alexandra Stănescu, Liviu Nicolae Ghilencea, \\ Dumitru Matei \\ Universitatea de Medicină şi Farmacie „Carol Davila“, Bucureşti, România
}

\begin{abstract}
High blood pressure is a global threat due to its consequences on morbidity and mortality through cardiovascular diseases such as myocardial infarction, stroke or chronic kidney disease.

In Romania the prevalence of hypertension has registered an upward trend of $45 \%$ of the general population equivalent of 7.4 million persons compared to $40 \%$ in 2011 .
\end{abstract}

Keywords: hypertension, cardiovascular disease, cardiovascular risk

REZUMAT

Hipertensiunea arterială reprezintă o ameninţare la nivel mondial din cauza consecinţelor sale privind morbiditatea şi mortalitatea prin bolile cardiovasculare precum infarctul miocardic, AVC sau boala cronică de rinichi.

În România, prevalenţa hipertensiunii arteriale a înregistrat un trend ascedent de $45 \%$ din populaţia generală, echivalent a 7,4 milioane de persoane, faţă de 40\% înregistrat în anul 2011.

Cuvinte cheie: hipertensiune arterială, boală cardiovasculară, risc cardiovascular

\section{INTRODUCERE}

La nivel european, hipertensiunea arterială înregistrează o prevalență între 30 şi 45\%, trendul fiind crescător odată cu vârsta $(1,2)$.

Ponderea pacienților hipertensivi care urmau tratament în România a crescut de la 59,2\% în 2012 la $75,2 \%$ în 2016, dar în continuare, pentru aproximativ $70 \%$ dintre aceştia, nu s-a obținut controlul hipertensiunii arteriale la valori sub 140/90 $\mathrm{mmHg}$, conform studiului SEPHAR III (3).

Sunt numeroase afecțiuni care asociază hipertensiunea arterială, cum sunt psoriazisul şi sindromul metabolic; acestea pot asocia hipertensiune arterială fiecare de sine stătător, cu un risc crescut atunci când pacientul are atât psoriazis, cât şi sindrom metabolic (4-6).
De asemenea, se ridică problema hipertensiunii arteriale la copii şi la gravide, aceste două categorii necesitând o atenție sporită din punct de vedere terapeutic, mai ales în cazul asocierii altor comorbidități cum este psoriazisul (7-9).

Scopul lucrării este reprezentat de rolul medicului de familie în prevenția bolilor cardiovasculare la pacienții hipertensivi, boli precum infarctul miocardic, AVC ischemic, boala arterială periferică sau boala cronică de rinichi prin modificarea stilului de viață, scăderea valorilor tensionale prin aplicarea tratamentului medicamentos antihipertensiv şi combaterea factorilor de risc cardiovascular asociaţi hipertensiunii arteriale. 


\section{Aspecte ale tratamentul hipertensiunii arteriale}

În primul rând, medicul va recomanda modificarea stilului de viaţă al pacientului hipertensiv, adică acele măsuri care se adresează combaterii factorilor de risc modificabili, şi anume renunţarea la fumat, reducerea greutăţii corporale corespunzătoare unui indice de masă corporală între 20 şi 25 $\mathrm{kg} / \mathrm{m}^{2}$, desfăşurarea de activitate fizică 2,5-5 ore pe săptămână de intensitate cel puțin moderată, scăderea ingestiei de alcool la 20 grame pe zi (echivalentul a 2 pahare la bărbați) şi 10 grame pe zi (adică un pahar în cazul femeilor), reducerea ingestiei de sare la un nivel sub 5 grame pe zi, creşterea consumului de fructe şi legume la un nivel de 30-45 grame de fibre pe zi obținut din 200 grame fructe pe zi (de 2-3 ori pe zi) şi 200 grame de legume zilnic (de 2-3 ori pe zi), consumul produselor lactate degresate $\mathrm{cu}$ conținut redus de grăsim saturate şi creşterea procentului de acizi graşi polinesaturați în alimentație rezultat din consumul a cel puțin două mese de peşte pe săptămână, dintre care una să fie de peşte oceanic $(10,11)$.

Studii recente au dus la reevaluarea țintei tensiunii arteriale sistolice de $130 \mathrm{mmHg}$, au fost evaluați pacienți cu tensiunea arterială sistolică $<140$ mmHg într-un grup şi $<120$ mmHg în alt grup, nu au fost diferențe semnificative între cele două grupuri din punct de vedere al infarctului miocardic, al decesului prin boală cardiovasculară sau al acidentului vascular, ceea ce a dus la creşterea pragului pentru iniţierea terapiei antihipertensive la 140 $\mathrm{mmHg}(12,13)$.

Valorile țintă pentru tensiunea arterială în populația general sunt sub $140 \mathrm{mmHg}$ pentru TAS şi sub 90 mmHg pentru TAD, iar în cazul pacienților diabetici se recomandă scăderea TAD sub $80 \mathrm{mmHg}$ (14).

În ceea ce priveşte măsurarea tensiunii arteriale în cabinet, este de preferat să fie folosite dispozitivele electronice (oscilometrice) ale brațului superior auscultării (gradul C); se consideră că o medie a tensiunii sistolice $\geq 140 \mathrm{~mm} \mathrm{Hg}$ sau diastolic $\geq 90$ mm Hg este ridicată, iar sistolica între 130 şi 139 mm Hg şi/sau diastolica între 85 şi 89 mm Hg este înalt-normală (gradul C) (15).

Recomandările de rutină în ceea ce priveşte testele de laborator ale persoanelor hipertensive includ: electrocardiograma şi biochimie, sumarul de urină, glicemie şi/sau hemoglobina glicozilată, colesterolul total, HDL-colesterolul, LDL-colesterolul şi trigliceridele, albuminuria la pacienții diabetici, în timpul fazei de întreținere a managementului hipertensiunii, testele (inclusiv cele pentru electro- liți, creatinină şi lipidele) trebuie repetate cu o frecvență în funcție de starea clinică a pacientului (15).

\section{Tratamentul medicamentos}

Tratamentul medicamentos al tensiunii arteriale se bazează pe administrarea separată sau combinată a principalelor clase de medicamente antihipertensive, şi anume diureticele tiazidice, inhibitorii enzimei de conversie a angiotensinei IEC, blocanți ai receptorilor de angiotensină $\mathrm{BRA}$, calciu-blocante BCC şi betablocante, aceste clase de medicamente exercitând un efect hipotensor relativ egal.

Indicația tratamentului antihipertensiv va ține cont de valoarea tensiunii arteriale şi de riscul cardiovascular al pacientului (16).

Pacienții cu hipertensiune de gradul 3 sau gradul 1 şi 2 , dar cu un risc cardiovasculat total înalt sau foarte înalt, au indicație pentru aplicarea tratamentului medicamentos imediat cu una sau mai multe clase de antihipertensive (17).

În cazul pacienților cu hipertensiune de grad 1 sau 2 şi cu risc cardiovascular total moderat, se vor indica măsurile cu privire la schimbarea stilului de viață pe o perioadă de câteva săptămâni, în timp la cei cu hipertensiune gradul 1 fără alți factori de risc cardiovascular se va indica tot schimbarea stilului de viață pentru câteva luni, urmând ca în funcție de efectul asupra scăderii tensiunii arteriale să se ia decizia administrării tratamentului medicamentos la momentul oportun (18).

Se recomandă ca, în cazul în care tensiunea arterială nu este controlată cu unul sau două antihipertensive, să nu se crească doza medicamentelor administrate, din cauza creşterii riscului efectelor adverse, şi să se asocieze un alt antihipertensiv dintr-o clasă diferită (19).

Ghidul European al Societății de Cardiologie recomandă în cazul asocierii medicației antihipertensive pentru scăderea şi controlul valorilor tensionale la pacienţii cu risc înalt folosirea a trei antihipertensive precum diuretic tiazidic cu IEC şi calciu-blocant DHP sau diuretic tiazidic cu blocant de receptor de angiotensină şi calciu-blocant DHP.

Riscul cardiovascular total reprezintă criteriul principal al aplicării tratamentului medicamentos la toți pacienții hipertensivi, iar calcularea lui se va ține cont de riscograma SCORE (20).

La pacienții cu risc scăzut sau moderat evaluat, conform scalei de risc SCORE, la calcularea riscului cardiovascular total trebuie luate în considerare şi afectarea subclinică de organ țintă precum HVS, prezența de plăci de aterom la nivel carotidian sau microalbuminurie $30-300 \mathrm{mg} / 24$ ore, deoarece 


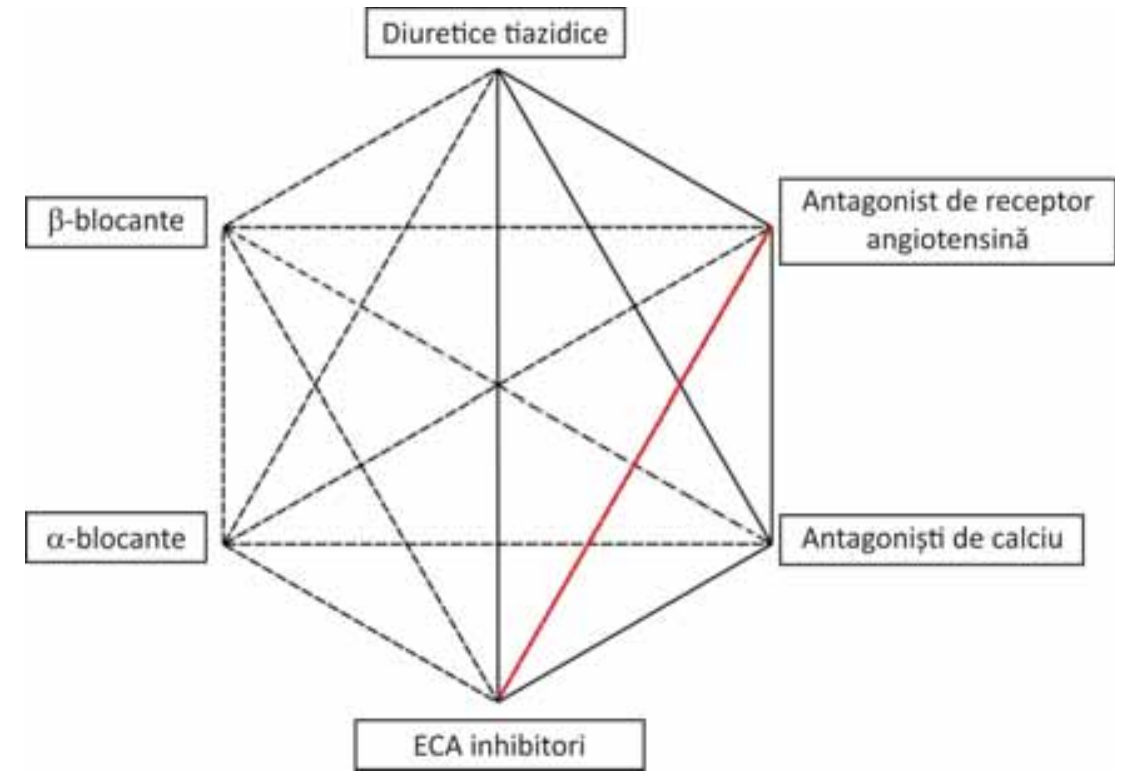

FIGURA 1. Regulile terapeutice de asociere a principalelor clase de medicamente antihipertensive

afectarea subclinică a organelor țintă în hipertensiune este considerată un predictor independent de mortalitate de cauză cardiovasculară (21).

În cazul pacienților cu factori de risc cardiometabolici precum dislipidemia sau toleranța alterată la glucoză, se indică evitarea betablocantelor şi a diureticelor tiazidice în schema de tratament deoarece cresc riscul apariţiei diabetului zaharat (22).

Persoanele cu diabet zaharat, cu BVC cunoscută, albumină crescută în urină, boală renală, trebuie să primească primească un inhibitor al enzimei de conversie a angiotensinei (ACE), un blocant al receptorilor de angiotensină (ARB) ca terapie de primă linie, acestea fiind în concordanţă cu Hypertension Canada şi Diabetes Canada, care s-au bazat pe studii clinice randomizate $(23,24)$.

Contraindicațiile diverselor clase de medicamente antihipertensive sunt reprezentate de gută în cazul diureticelor tiazidice, de astmul bronşic sau blocul atrioventricular de gradul 2 sau 3 în cazul betablocantelor, de sarcină, hiperpotasemie, edem angioneurotic sau stenoză bilaterală de arteră renală în cazul inhibitorilor de enzimă de conversie ai angiotensinei, de sarcină, hiperpotasemie sau stenoză bilaterală de arteră renală în cazul blocanților receptorilor de angiotensină, de insuficiența ventriculară stângă severă sau blocul atrioventricular de gradul 2 sau 3 pentru blocantele canalelor de calciu nondihidropinice sau insuficiența renală acută ori cronică severă (RFG sub $30 \mathrm{ml} / \mathrm{min}$ ) în cazul diureticelor antialdosteronice.

Pe lângă scăderea valorilor tensionale, diversele clase de medicamente antihipertensive au şi efecte de clasă care le indică în diverse afecțiuni asociate hipertensiunii arteriale. Astfel, în cazul afectării de organe țintă precum HVS, sunt indicate IECA, BCC sau BRA, în ateroscleroză sunt indicate IECA şi BCC, cu efect favorabil atât pe scăderea valorilor tensionale, cât şi în regresia plăcilor de aterom şi stabilizarea acestora, sau IECA şi BRA în nefoangioscleroză cu microalbuminurie $(25,26)$.

În cazul bolilor cardiovasculare asociate HTA precum infarctul miocardic sechelar se indică administrarea betablocantelor, IECA, BRA, în cazul bolii cardiace ischemice - administrarea de betablocant şi BCC, în cazul insuficienței cardiace administrarea de diuretic, antialdosteronic, betablocant, IECA sau BRA, în cazul anevrismului de aortă - administrarea de betablocant. Pentru prevenirea apariției fibrilației atriale, efect favorabil au administrarea de BRA, IECA, betablocantele şi diureticele antialdosteronice, iar în ceea ce priveşte controlul alurii ventriculare, sunt utile betablocantele şi $\mathrm{BCC}$ non-dihidropiridine, în boala cronică de rinichi sunt utile IECA şi BRA, iar în boala arterială periferică sunt de preferat IECA şi cu BCC de tipul dihidropiridinelor $(25,26)$.

La pacienții vârstnici cu HTA sistolică izolată, este de preferat administrarea diureticelor şi a BCC (27).

La pacienții cu sindrom metabolic, efecte favorabile au IECA, BRA şi BCC. Efecte favorabile cardiometabolice în cazul diabetului zaharat asociat HTA au IECA şi BRA. La femeile gravide, se preferă administrarea metil-dopa, a betablocantelor şi a BCC (28). 
La pacienții de rasă neagră, s-a observat efectul favorabil al diureticelor asociate cu BCC.

\section{Tratamentul factorilor de risc asociaţi}

Tratamentul complex al hipertensiunii arteriale se referă nu numai la scăderea valorilor tensionale, ci şi la tratamentul celorlați factori de risc cardiovascular precum dislipidemia sau diabetul zaharat.

Pacienții hipertensivi ce asociază diabet zaharat sau au un risc SCORE $>5 \%$ vor primi tratament hipolipemiant cu statine ce exercită şi un efect de stabilizare a plăcilor de aterom (29).

Scăderea valorilor glicemiei reprezintă o altă verigă importantă la pacientul hipertensiv deoarece este dovedit că diabetul zaharat este un factor de risc cardiovascular major.

Tratamentul antidiabetic oral se va face de primă intenție cu metformin, dacă nu există contraindicații, care face parte din clasa biguanide - cu efect pe scăderea rezistenței la insulină pentru atingerea țintei terapeutice în cazul HbA1c de sub 7\% (30).

Pacienții cu antecedente patologice de boală cardiovasculară aterosclerotică - precum boala coronariană ischemică, infarct miocardic sechelar, AVC ischemic ateromatoză carotidiană, boală arterială periferică - au indicație pentru tratament antiagregant plachetar cu aspirină în doză de 75-100 $\mathrm{mg} / \mathrm{zi}(31)$.

Pacienților cu intoleranță gastrică sau bronhospasm la aspirină li se va administra clopidogrel 75 $\mathrm{mg} / \mathrm{zi}$.

În ceea ce priveşte terapia combinată, s-a efectuat un studiu pe 6.946 de participanti cu diabet zaharat de tip 2. 2.842 de participanți au fost considerați „cu risc ridicat", din cauza unui precedent cardiac, cerebrovascular sau renal. Concluziile studiului au arătat că asocierea benazepril/amlodipina a redus apariţia evenimentului primar comparativ cu benazepril/tiazid la toți subiecții cu diabet zaharat $(8,8 \%$ vs $11 \%$, HR 0,79 , CI 95\% CI 0,68-0,92) şi la subgrupul de subiecți care au fost considerați cu ris ridicat (13,6 vs. $17,3 \%$, HR 0,77, CI 95\% 0,64$0,93)(32)$.

În cazul pacienților hipertensivi tineri cu vârsta sub 40 ani, trebuie luată în calcul o posibilă cauză secundară de hipertensiune. Cele mai frecvente cauze de hipertensiune secundară sunt reprezentate de bolile renale (precum cele renoparenchimatoase, GNC, boala polichistică renală, nefropatia diabetică, pielonefrita), cauzele renovasculare - stenoza aterosclerotică de arteră renală, vasculita, ocluzia de arteră renală prin tromboză sau embolie -, boli endocrine precum hiperaldosteronism primar (sin- drom Conn), hipertiroidia, acromegalia, secreția medulosuprarenală în exces de catecolamine (feocromocitom), secreția în exces a glucocorticoizilor sau tratament cu antiinflamatorii steroidiene (boală/sindrom Cushing) sau alte situații clinice predispozante precum sindromul de apnee în somn, sarcina cu eclampsia, coarctația de aortă, precum şi afecțiunile neurologice precum hipertensiunea intracraniană. La această categorie de pacienți, medicul de familie trebuie să determine posibila cauză secundară de hipertensiune secundară prin efectuarea unei anamneze complete, determinarea semnelor sau simptomelor sugestive, examen clinic şi probe biologice. Pentru confirmarea diagnosticului de HTA secundară, medicul de familie va colabora cu medicii specialişti (cardiolog, internist, urolog, nefrolog, endocrinolog, neurolog, pneumolog) în vederea efectuării de investigații paraclinice precum ecografie Doppler, CT sau RMN cu substanţă de contrast, angio RMN cu substanţă de contrast, angiografia intraarterială renală, poligrafia ventilatorie nocturnă.

\section{CONCLUZII}

Populația României a înregistrat o incidență în creştere a hipertensiunii arteriale, fenomen explicabil prin îmbătrânirea populației şi adoptarea unui stil de viață nesanogenetic de către cei mai tineri.

Medicul de familie are un rol cheie în diagnosticarea pacienților cu hipertensiune arterială şi prevenirea bolilor cardiovasculare asociate hipertensiunii arteriale precum infarctul miocardic, AVC ischemic sau boala arterială periferică prin recomandarea schimbării stilului de viaţă şi prin administrarea tratamentului antihipertensiv în funcție de comorbidități şi de factorii de risc cardiovascular asociaţi.

În cadrul activității de dispensarizare a pacienților hipertensivi, în vederea creşterii complianței la tratament şi la măsurile de schimbare a stilului de viață, medicul de familie va trebui să dezvolte o comunicare empatică cu pacientul, să explice acestuia legătura dintre stilul de viaţă şi hipertensiunea arterială, împreună cu complicațiile acesteia precum bolile cardiovasculare, să încurajeze pacientul în sensul identificării factorilor de risc ce trebuie modificați şi să monitorizeze permanent progresele pacientului.

În cazul pacienților tineri, medicul de familie va trebui să ia în considerare o eventuală cauză secundară de HTA.

Pacienții hipertensivi vor fi evaluați cel puțin o dată la 2 ani din punctul de vedere al factorilor de 
risc cardiovascular asociați şi al afectării asimptomatice de organ țintă.

O regresie în ceea ce priveşte afectarea de organe țintă reflectă un control eficient al tensiunii arte- riale şi protecția pacientului față de bolile cardiovasculare pe termen lung.

Conflict of interest: none declared Financial support: none declared

\section{BIBLIOGRAFIE}

1. Pereira M., Lunet N., Azevedo A., Barros H. Differences in prevalence, awareness, treatment and control of hypertension between developing and developed countries. J Hypertens 2009; 27:963-975.

2. Costanzo S., Di Castelnuovo A., Zito F., Krogh V., Siani A., Arnout J. et al. Prevalence, awareness, treatment and control of hypertension in healthy unrelated male-female pairs of European regions: the dietary habit profile in European communities with different risk of myocardial infarction: the impact of migration as a model of geneenvironment interaction project. J Hypertens 2008; 26:2303-2311.

3. Dorobantu M., Tautu O.F., Dimulescu D., Sinescu C., GusbethTatomir P., Arsenescu-Georgescu C., Mitu F., Lighezan D., Pop C., Babes K., Giuca A., Branza I., Udrescu M., Herdea V., Darabont R. Perspectives on hypertension's prevalence, treatment and control in a high cardiovascular risk East European country: Data from the SEPHAR III survey. J Hypertens. 2018 Mar; 36(3):690-700

4. Stănescu A.M.A, Matei A., Grăjdeanu I.V., Appiah E.A., Giurcăneanu C. The multifactorial approach in the management of psoriasis and its associated comorbidities. Revista Practica Medicală 2016; 11,1(43): 49-52

5. Stănescu A.M.A, Matei A., I Grăjdeanu I.V., Appiah E.A., Paparău C., Giurcăneanu C. Asocierea între psoriazis şi sindromul metabolic, corelată cu deficitul vitaminei D în ambele afecţiuni. Revista Medicală Română 2016; 1: 81-85

6. Stănescu A.M.A., Goanta A.M., Ignatescu R., Appiah E.A., Grăjdeanu I.V., loniţă L. Aspecte comparative la om şi animal în diagnosticul sindromului metabolic şi disfuncţiei metabolice asociate obezităţii. Revista Practica Medicală 2017; 12, 4(53): 250-255

7. Stănescu A.M.A, Grăjdeanu I.V., Diaconu C., lancu M.A., Ştefani C. Evoluţia psoriazisului prenatal şi postnatal, afectarea fătului, modificari imune şi hormonale, tratament. Practica Medicala. Vol.13, Nr. 1(54): 2018; 36-40.

8. Stănescu A.M.A, Diaconu C., lancu M.A., Bejan G.C., Ştefani C., Grăjdeanu I.V. Psoriazisul şi bolile cardiovasculare: Actualităţi în cercetarea medicală, Revista Medicală Română, Vol LXV, Nr. 1: 2018; 41-44

9. Stănescu A.M.A., Grăjdeanu I.V., Appiah E.A., Bejan G.C. Abordare diferenţiată a psoriazisului în funcţie de vârsta pacientului. Practica Medicală Vol. 12, Nr.4(53): 2017; 204-207

10. Verberk W.J., Kroon A.A., Lenders J.W., Kessels A.G., van Montfrans G.A., Smit A.J. et al. Self-measurement of blood pressure at home reduces the need for antihypertensive drugs: A randomized, controlled trial. Hypertension 2007; 50:1019-1025.

11. Dickinson H.O., Mason J.M., Nicolson D.J., Campbell F., Beyer F.R., Cook J.V. et al. Lifestyle interventions to reduce raised blood pressure: A systematic review of randomized controlled trials. J Hypertens 2006; 24:215-233.

12. G. Mancia, R. Fagard, K. Narkiewicz et al. 2013 ESH/ESC guidelines for the management of arterial hypertension: The task force for the management of arterial hypertension of the European Society of Hypertension (ESH) and of the European Society of Cardiology (ESC), Eur Heart J, 34 (2013), pp. 2159-2219

13. P.A. James, S. Oparil, B.L. Carter et al. 2014 evidence-based guideline for the management of high blood pressure in adults: Report from the panel members appointed to the Eighth Joint National Committee (JNC 8), JAMA, 311 (2014), pp. 507-520

14. UK Prospective Diabetes Study Group Tight blood pressure control and risk of macrovascular and microvascular complications in type 2 diabetes: UKPDS 38. Br Med J 1998; 317:703-713.

15. Stella S. Daskalopoulou, Doreen M. Rabi, Kelly B. Zarnke et al. The 2015 Canadian Hypertension Education Program Recommendations for Blood Pressure Measurement, Diagnosis, Assessment of Risk, Prevention, and Treatment of Hypertension, Canadian Journal of Cardiology, Volume 31, Issue 5, 2015, Pages 549-568,

16. Perk J., De Backer G., Gohlke H., Graham I., Reiner Z., Verschuren M. et al. European Guidelines on cardiovascular disease prevention in clinical practice (version 2012): The Fifth Joint Task Force of the European Society of Cardiology and Other Societies on Cardiovascular Disease Prevention in Clinical Practice (constituted by representatives of nine societies and by invited experts) Developed with the special contribution of the European Association for Cardiovascular Prevention \& Rehabilitation (EACPR). Eur Heart $J$ 2012; 33:1635-1701.

17. Collins R., Mac Mahon S. Blood pressure, antihypertensive drug treatment and the risks of stroke and of coronary heart disease. $\mathrm{Br}$ Med Bull 1994; 50:272-298.

18. Zanchetti A., Grassi G., Mancia G. When should antihypertensive drug treatment be initiated and to what levels should systolic blood pressure be lowered? A critical re-appraisal. J Hypertens 2009; 27:923-934.

19. Wald D.S., Law M., Morris J.K., Bestwick J.P., Wald N.J. Combination therapy vs. monotherapy in reducing blood pressure: Meta-analysis on 11,000 participants from 42 trials. Am JMed 2009; 122:290-300.

20. Conroy R.M., Pyorala K., Fitzgerald A.P., Sans S., Menotti A., De BackerG. et al. Estimation often-year risk of fatal cardiovascular disease in Europe: The SCORE project. Eur Heart J 2003; 24:9871003.

21. Sehestedt T., Jeppesen J., Hansen T.W., Rasmussen S., Wachtell K., Ibsen H. et al. Thresholds for pulse wave velocity, urine albumin creatinine ratio and left ventricular mass index using SCORE, Framingham and ESH/ESC risk charts. J Hypertens 2012; 30:19281936.

22. Elliott W.J., Meyer P.M. Incident diabetes in clinical trials of antihypertensive drugs: A network meta-analysis. Lancet 2007; 369:201-207.

23. A.A. Leung, K. Nerenberg, S.S. Daskalopoulou et al. Hypertension Canada's 2016 Canadian Hypertension Education Program Guidelines for blood pressure measurement, diagnosis, assessment of risk, prevention, and treatment of hypertension, Can J Cardiol, 32 (2016), pp. 569-588

24. R.E. Gilbert, D. Rabi, P. LaRochelle et al. Canadian Diabetes Association 2013 Clinical Practice Guidelines for the Prevention and Management of Diabetes in Canada: Treatment of hypertension, Can J Diabetes, 37 (Suppl. 1) (2013), pp. S117-S118

25. van Vark L.C., Bertrand M., Akkerhuis K.M., Brugts J.J., Fox K., Mourad J.J., Boersma E. Angiotensin-converting enzyme inhibitors reduce mortality in hypertension: A meta-analysis of randomized clinical trials of renin-angiotensin-aldosterone system inhibitors involving 158998 patients. Eur Heart J 2012; 33:2088-2097

26. Costanzo P., Perrone-Filardi P., Petretta M., Marciano C., Vassallo E., Gargiulo P. et al. Calcium channel blockers and cardiovascular 
outcomes: A meta-analysis of 175634 patients. J Hypertens 2009; 27:1136-1151.

27. Beckett N.S., Peters R., Fletcher A.E., Staessen J.A., Liu L., Dumitrascu $D$. et al. Treatment of hypertension in patients 80 years of age or older. N Engl J Med 2008; 358:1887-1898.

28. Regitz-Zagrosek V., Blomstrom Lundqvist C., Borghi C., Cifkova R., Ferreira R., Foidart J.M. et al. ESC Guidelines on the management of cardiovascular diseases during pregnancy: The Task Force on the Management of Cardiovascular Diseases during Pregnancy of the European Society of Cardiology (ESC). Eur Heart J $2011 ; 32: 3147-3197$

29. Taylor F., Ward K., Moore T.H., Burke M., Davey Smith G., Casas J.P., Ebrahim S. Statins for the primary prevention of cardiovascular disease. Cochrane Database Syst Rev 2011;CD004816.
30. Gerstein HC, Miller ME, Genuth S, Ismail-Beigi F, Buse JB, Goff $\mathrm{DC} \mathrm{Jr}$, et al. Long-term effects of intensive glucose lowering on cardiovascular outcomes. N Engl J Med 2011; 364:818-828.

31. Baigent C., Blackwell L., Collins R., Emberson J., Godwin J., Peto R. et al. Aspirin in the primary and secondary prevention of vascular disease: Collaborative meta-analysis of individual participant data from randomised trials. Lancet 2009; 373:1849-1860.

32. M.A. Weber, G.L. Bakris, K. Jamerson et al. Cardiovascular events during differing hypertension therapies in patients with diabetes. $J \mathrm{Am}$ Coll Cardiol, 56 (2010), pp. 77-85. 